\title{
Rum adulteration detection using an optical fiber sensor based on multimodal interference (MMI)
}

\section{Detección de adulteración de ron empleando un sensor de fibra óptica basado en interferencia multimodal (MMI)}

\author{
A. J. Rodríguez Rodríguez ${ }^{(1)}$, D. G. Martínez Camacho(1), K. González Gutiérrez ${ }^{(1)}$, \\ D. A. May Arrioja ${ }^{(1)}$, R. F. Domínguez Cruz(1), I. R. Matías Maestro(2), C. Ruiz Zamarreño ${ }^{(2, *)}$ \\ 1. Departamento de Ingeniería Electrónica, Universidad Autónoma de Tamaulipas, 88779 Reynosa Tamaulipas, \\ Mexico. \\ 2. Departamento de Ingeniería Eléctrica y Electrónica, Universidad Pública de Navarra, 31006 Pamplona, Spain.
}

(*) Email: carlos.ruiz@unavarra.es

Received / Recibido: 19/09/2013. Revised / Revisado: 11/11/2013. Accepted / Aceptado: 18/11/2013.

DOI: http://dx.doi.org/10.7149/OPA.46.4.345

\begin{abstract}
:
In this work, we propose and demonstrate the fabrication of an optical fiber sensor based on multimode interference effects (MMI) for rum quality control. The operation of the sensor relies on the fact that when rum is adulterated, which can be done either with ethanol or ethylene glycol, the refractive index (RI) of the adulterated rum will be different as compared to the original rum. Since the white rum (Bacardi $($ ) has a RI close to 1.345 and the highest RI of the contaminant is 1.412 (ethylene glycol), the RI of the adulterated rum will increase as the volume of the contaminant is increased. Therefore, considering that the MMI sensor exhibits a sensitivity of $258.06 \mathrm{~nm} / \mathrm{RIU}$ for liquids with RI ranging from 1.318 to 1.4203 , we can accurately determine if a rum sample is free of contaminants or adulterated with other liquid, which is typically performed using ethanol or toxic elements like ethylene glycol. Although the sensor cannot determine which kind of liquid is altering the rum, it can easily detect when the original rum has been adulterated, even with small amounts of liquid. The sensor also provides high repeatability and reversibility while using a fast and simple fabrication process.
\end{abstract}

Key words: Optical Fiber, Refractometer, Multimodal Interference, Refractive Index, Sensor, Anhydrous Ethanol, Ethylene Glycol.

\section{RESUMEN:}

En este trabajo se propone y demuestra la fabricación de un sensor de fibra óptica basado en el efecto de interferencia multimodal (MMI) para el control de calidad del ron. La operación del sensor se basa en el hecho de que cuando el ron es adulterado, lo que puede hacerse con etanol o etilenglicol, el índice de refracción (IR) del ron adulterado será diferente cuando se compara con el ron original. Siendo que el ron blanco (Bacardiß) tiene un IR cercano a 1.345 y que el IR más alto del contaminante es 1.412 (etilenglicol), el IR del ron adulterado se incrementará conforme se incrementa el volumen del contaminante. Por lo tanto, considerando que el sensor MMI tiene una sensibilidad de $258.06 \mathrm{~nm} / \mathrm{RIU}$ para líquidos con IR entre 1.318 y 1.4203, podemos entonces determinar de forma precisa si una muestra de ron está libre de contaminantes o adulterada con otro líquido, lo que se realiza comunmente usando etanol o elementos tóxicos como el etilenglicol. Aunque el sensor no puede determinar que tipo de líquido esta modificando al ron, puede fácilmente detectar cuando el ron original ha sido adulterado, aun con cantidades pequeñas de líquido. El sensor proporciona además alta repetitividad and reversibilidad manteniendo un proceso de fabricación rápido y simple.

Palabras clave: Fibra Óptica, Refractómetro, Interferencia Multimodal, Índice de Refracción, Sensor, Etanol Anhidro, Etilenglicol. 


\section{REFERENCES AND LINKS / REFERENCIAS Y ENLACES}

[1]. J. Roldan, C. Frauca, A. Duenas, “Intoxicación por alcoholes”, Anales Sis San Navarra 26, 129-139, (2003). DOI

[2]. J. Brent, "Current management of ethylene glycol poisoning”, Drugs 61, 979-988 (2001). DOI

[3]. A. Smith, "Spice keeps rum moving in Europe", The International Wine \& Spirit Research Magazine 1012 (2012).

[4]. R. C. Young, W. J. Buttner, B. R. Linnell, R. Ramesham, "Electronic nose for space program applications", Sensor. Actuat. B - Chem. 93, 7-16 (2003).

[5]. A. Branca, P. Simonian, M. Ferrante, E. Novas, R. Martin Negric, "Electronic nose based discrimination of a perfumery compound in a fragrance”, Sensor. Actuat. B - Chem. 92, 222-227 (2003).

[6]. S. Ampuero, J. O. Bosset, "The electronic nose applied to dairy products: A review", Sensor. Actuat. B Chem. 94, 1-12 (2003).

[7]. http://www.enwaveopt.com/doc/MethanolinAlcohol.pdf

[8]. L. S. Mendes, F. C. C. Oliveira, P. A. Z. Suarez, J. C. Rubim, "Determination of ethanol in fuel ethanol and beverages by Fourier transform (FT)-near infrared and FT-Raman spectrometries”, Anal. Chim. Acta 493, 219-231 (2003).

[9]. R. Y. Sato-Berrú, J. Medina-Valtierra, C. Medina-Gutiérrez, C. Frausto-Reyes, “Quantitative NIR Raman analysis in liquid mixtures", Spectrochim. Acta A 60, 2225-2229 (2004). DOI

[10]. I. Heberle, A. Liebminger, U. Weimar, W. Gopel, "Optimised sensor arrays with chromatographic preseparation: Characterisation of alcoholic beverages", Sensor. Actuat. B - Chim. 68, 53-57 (2000).

[11]. O. Barbosa-García, G. Ramos-Ortíz, J. L. Maldonado, J. L. Pichardo-Molina, M. A. Meneses-Nava, J. E. A. Landgrave, J. Cervantes-Martínez, "UV-VIS absorption spectroscopy and multivariate analysis as a method to discriminate tequila", Spectrochim. Acta A 66, 129-134 (2007). DOI

[12]. U. Contreras, O. Barbosa-García, J. L. Pichardo-Molina, G. Ramos-Ortíz, J. L. Maldonado, M. A. MenesesNava, N. E. Ornelas-Soto, P. L. López-de-Alba, "Screening method for identification of adulterate and fake tequilas by using UV-VIS spectroscopy and chemometrics", Food Res. Int. 43, 2356-2362 (2010). DOI

[13]. G. Martínez-López, D. Luna-Moreno, D. Monzón-Hernández, R. Valdivia-Hernández, “Optical method to differentiate tequilas based on angular modulation surface plasmon resonance", Opt. Lasers Eng. 49, 675-679 (2011). DOI

[14]. A. Yildirim, F. E. Ozturk, M. Bayindir, "Smelling in chemically complex environments: An optofluidic Bragg fiber array for differentiation of methanol adulterated beverages", Anal. Chem. 85, 6384-639 (2013). DOI

[15]. M. Morisawa, S. Muto, "Plastic optical fiber sensing of alcohol concentration in liquors", J. Sensors 2012, 709849 (2012). DOI

[16]. C. Elosua, C. Bariain, A. Luquin, M. Laguna, I. R. Matias, "Optical fiber sensors array to identify beverages by their odor", IEEE Sens. J. 12, 3156-3162 (2012). DOI

[17]. Y. Kurauchi, T. Yanal, N. Egashira, K. Ohga, "Fiber-optic sensor with chitosan/poly(vinyl alcohol) cladding for determination of ethanol in alcoholic beverages", Anal. Sci. 10, 213-217 (1984). DOI

[18].Z. H. Zhang, R. Lockwood, J. G. C. Veinot, A. Meldrumb, "Detection of ethanol and water vapor with silicon quantum dots coupled to an optical fiber", Sensor. Actuat. B - Chem. 181, 523- 528 (2013).

[19]. Q. Wang, G. Farrell, "All-fiber multimode-interference-based refractometer sensor: proposal and design", Opt. Lett. 31, 317-319 (2006). DOI

[20].J. E. Antonio López, D. López Cortes, M. A. Basurto Pensado, D. A. May Arrioja, J. J. Sánchez Mondragón, "All-fiber multimode interference refractometer sensor", Proc. SPIE 7316, 73161F (2009). DOI

[21]. Q. Wu, Y. Semenova, P. Wang, G. Farrell, "High sensitivity SMS fiber structure based refractometer Analysis and experiment", Opt. Express 19, 7937-7944 (2011). DOI

[22]. T. Walbaum, C. Fallnich, "Multimode interference filter for tuning of a mode-locked all-fiber erbium laser", Opt. Lett. 36, 2459-2461 (2011). DOI 
[23]. F. Hoytt, "New table of the refractive index of pure glycerol at $20^{\circ} \mathrm{C}$ ", Ind. Eng. Chem. 26, 329-332 (1934). DOI

[24].S. Kedenburg, M. Vieweg, T. Gissibl, H. Giessen, "Linear refractive index and absorption measurements of nonlinear optical liquids in the visible and near-infrared spectral region", opt. Mater. Express 2, 1588-1611 (2012). DOI

\section{Introduction}

Throughout history, traditional alcoholic beverages of each region or country have been produced since many of them are representative of the country of origin. A standard practice in most countries, which is required by law, is to specify how much alcohol (ethanol) is contained in an alcoholic beverage. This is typically done by displaying on the bottle label the percentage of alcohol by volume. Based on the type of beverage this percentage can range from $7 \%$ up to more than $50 \%$. The key objective of such regulations is to maintain the quality of the beverage, but mainly to prevent harm to human beings due to alcohol intoxication. In the last decade, the adulteration of alcoholic beverages has been a common malpractice in order to increase the revenues of businesses dealing with their commercialization. Adulterated alcoholic beverages are legal alcoholic products that have been illicitly tampered with, for instance, by criminally diluting them with water, purposely putting them into new containers to conceal their true origin or adding toxic substances to manipulate the qualities of alcoholic beverages. Regardless of the quality degradation, the main issue is related to poisoning or death due to such malpractice. Ethanol has been widely used to manipulate alcoholic beverages and although the mortality associated with acute ethanol intoxication is rare, it can be an important factor when combined with other drugs. It is also directly responsible for more than half of traffic accidents. Meanwhile, ethylene glycol (EG) is used in the adulteration of alcoholic beverages as a solvent and antifreeze, and the toxicity is due to the accumulation of metabolites $[1,2]$.

Among the variety of commercial alcoholic beverages, rum is the most consumed worldwide [3], which makes it an easy target for adulteration. In México, for instance, six out of ten bottles are either adulterated or counterfeited with ethanol and EG. As a result, instruments that can accurately detect contaminants in alcoholic beverages are highly desirable. Electronic methods have been previously proposed to recognize and detect impurities in alcoholic beverages [4-6]. Although these electronic sensors have efficient results for the measurement of liquid impurities, they may be sensitive to electromagnetic interference, expensive, and unsuitable for remote operation. Optical technologies on the other hand are well suited for this task. Raman spectrometry [7], Fourier transform (FT) near infrared and Raman spectrometries [8], NIR Raman analysis [9], and gas-chromatography methods [10] has been also used to detect the presence of methanol and ethanol dissolved in alcohol beverages. For instance similar methods have been applied to detect adulteration in tequilas $[11,12]$. The main issue with such techniques is that the equipment is very expensive. Other technique based on surface plasmon resonance (SPR) [13] has been also reported. However, the system tends to be bulky and susceptible to external disturbances that can misalign the system.

A simple alternative that could offer high sensitivity, immunity to electromagnetic interference, reduced size, high resolution, low cost, and the possibility for multiplexed operation is based in optical fiber sensors. Some approaches have been investigated using optofluidic Bragg fiber array [14], plastic optical fibers [15], optical fiber sensor arrays [16] has been reported. Additionally, other works incorporate thin films around the fiber [17] and quantum dots [18] attached to the optical fiber. However, the main inconvenient in these systems is the need for special preparation of the fiber or the deposition of a sensitive material. A fiber sensor that can be suited for the detection of adulterated alcoholic beverages is the one based on multimode interference (MMI) effects. MMI devices can be very sensitive to RI changes of liquids [19-21] and, since this a parameter that is modified when ethanol or EG is added to an alcoholic beverage, they are well suited for this work. In this work we demonstrate the 
application of a MMI fiber sensor as a tool to monitor the adulteration of rum with another liquid, which is typically performed using either ethanol or ethylene glycol. Although the sensor cannot determine which kind of liquid is altering the rum, it can easily detect when the original rum has been adulterated, even with small amounts of liquid. The sensor can be operated by following either spectral shifts or intensity changes as long as external intensity fluctuations are removed from the experimental setup. The advantages of the sensor are that its fabrication is straightforward, and exhibits great reproducibility and reversibility, with no significant interference against temperature or humidity.

\section{Principle of operation}

A shown in Fig. 1, a MMI fiber structure is fabricated by just splicing a section of multimode fiber (MMF) between two single mode fibers (SMF). When an optical signal is launched into the MMF it excites all the supported modes of the MMF, and as the modes propagate along the MMF their interference gives rise to an interference carpet that is highly dependent with the phase relationship between the modes. At certain lengths, where the phase difference is a multiple of $2 \pi$, we have the formation of selfimages which are an exact replica of the input field. Therefore, by carefully selecting the length of the MMF, light coupled trough the input SMF will be imaged with small losses to the output SMF.

The MMF length at which the self-images occur, for a particular wavelength, can be calculated using the following equation [20],

$$
L=p \frac{n_{M M F} D_{M M F}^{2}}{\lambda_{0}} \quad \text { with } p=0,1,2 \ldots
$$

where $n_{M M F}$ and $D_{M M F}$ correspond respectively to the effective refractive index and diameter of the fundamental mode of the MMF, and $\lambda_{0}$ is the free space wavelength. As indicated in Eq. (1),

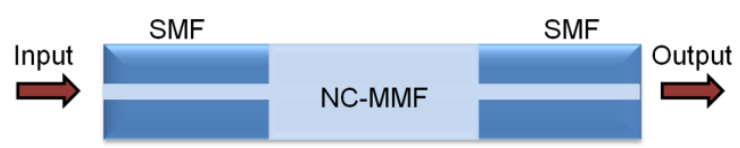

Fig. 1. Schematic of MMI structure. the self-images are periodically formed along the MMF segment. However, as shown in Fig. 2(a), we are interested in every fourth self-image since they have minimum losses as compared to other images. The self-images with higher losses are correlated with bigger phase errors between the propagating modes as compared to the required phase difference of $2 \pi$ to reproduce the input field, and thus the intensity of the selfimage is reduced. After the MMF is cleaved at the length dictated by Eq. (1), light with wavelength $\lambda_{0}$ will be transmitted with minimum loss through the MMI structure. However, when the devices are detuned from this design wavelength, the image will be formed either before or after the facet of the output SMF and the transmitted intensity will have higher losses. Therefore, the response of the MMI sensor under a wide spectrum source will be similar to a band-pass filter as shown in Fig. 2(b). According
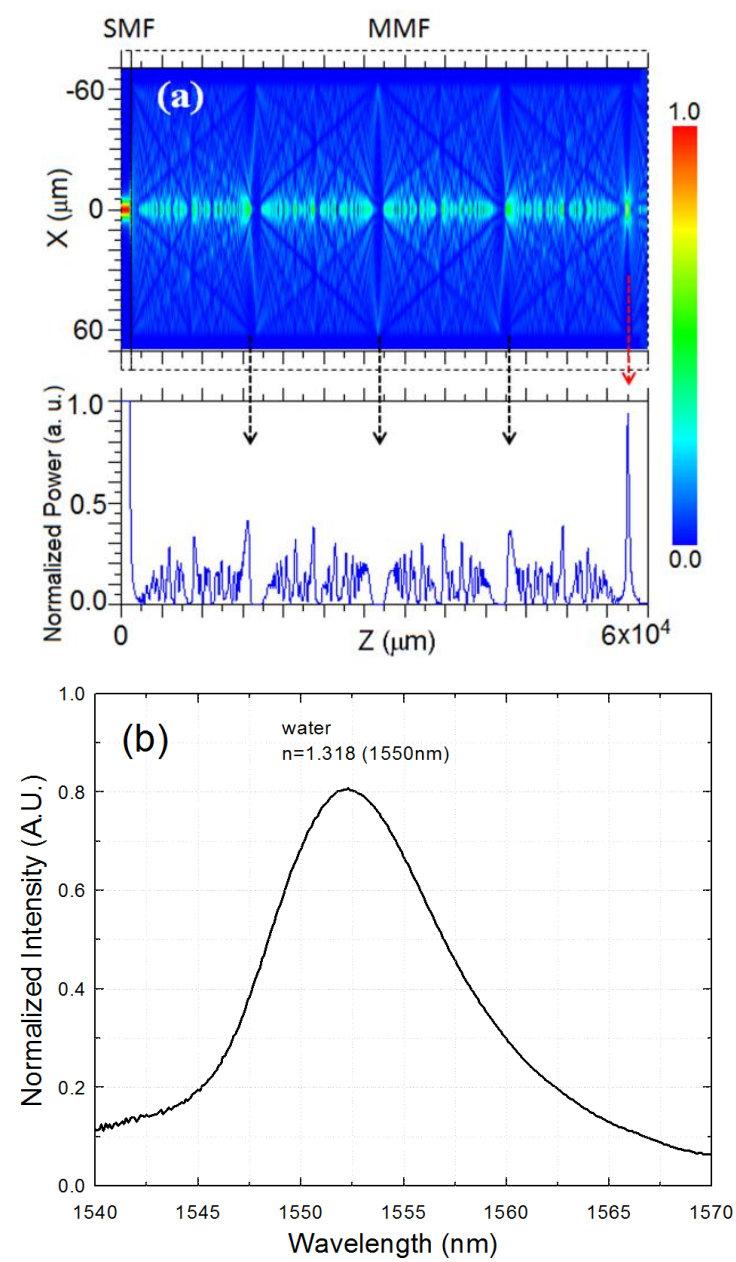

Fig. 2. (a) Light propagation in an MMI fiber device at 1550 $\mathrm{nm}$, and (b) MMI spectral response in water. 
to Eq. (1), by modifying the effective refractive index and diameter of the MMF the MMI peak wavelength can be spectrally shifted. In order to make the MMF sensitive to external perturbations we use a special MMF know as Nocore fiber (NC-MMF), which is basically a MMF without cladding (i.e. the cladding is air). Therefore, when the NC-MMF is immersed in a liquid, the effective refractive index and diameter of the NC-MMF will be modified and the spectral shift can be used to determine the refractive index of the liquid.

\section{Experimental procedure}

The NC-MMF used in our experiments is provided by Prime Optical Fiber Corporation. Prior to fabricating the MMI sensor we need to obtain the exact length of the NC-MMF that will provide the desired MMI peak wavelength. The length of the NC-MMF is calculated using Eq. (1) for a wavelength of $1550 \mathrm{~nm}$. The effective RI and diameter correspond to values of $n_{M M F}=1.444$ and $D_{M M F}=125 \mu \mathrm{m}$. Using these values in Eq. (1), for the case of the fourth selfimage $(p=4)$, we obtain a length of $58.22 \mathrm{~mm}$ for the NC-MMF. The MMI sensor is fabricating by first splicing the NC-MMF to a SMF using standard splicing procedures. It is important to mention that the polymer cladding around the NC-MMF is entirely removed. In fact, after mechanically stripping the polymer, the NCMMF is immersed in acetone to eliminate any residue. Using a micrometer, we can then control the length of the NC-MMF to be cleaved with a length of $58.22 \mathrm{~mm}$. After cleaving, this end is splicing to the output SMF and the MMI sensor is ready for testing. The experimental setup for testing the MMI sensors is shown in Fig. 3. The broadband optical source was a superluminescent diode (SLD) centered at $1550 \mathrm{~nm}$. The SLD is connected to the input SMF of the device, and the output SMF is then connected to an optical spectrum analyzer (OSA) Anritsu MS9740A to capture the transmitted spectrum. The SLD was operated using current and temperature controllers, Thorlabs LDC220C and TED200C respectively, in order to avoid intensity fluctuations from the optical source. Sharp radius of curvature were also eliminated and the remaining fiber was fixed to the optical table to prevent intensity variations from the optical fiber itself.

As shown in Fig. 3 the sensor was fixed in a channel which was then covered to form small chamber. The chamber included input and output plastic tubes to facilitate insertion and removal of the liquids. We should also mention that when an MMI device is bent the MMI spectral response could be also shifted [22]. However, such effect is observed for small radius of curvature (i.e. large bending) which is not the case in our experimental setup. Nevertheless, in the case of intensity measurements, the MMI sensor is tensioned using a weight of $25 \mathrm{gr}$ to minimize any bending due to surface tension in the channel. In the case of spectral measurements a weight of $5 \mathrm{gr}$ is used, which guarantees that no spectral shifts are observed regardless of slight intensity variations, while maintaining the fiber with small tension. In addition, since both optical fibers and liquids are sensitive to temperature, the measurements were performed at a controlled temperature of $25^{\circ} \mathrm{C}$.

Regarding the rum used in our experiments, although we have a wide range of brands available in the market, we selected Bacardi ${ }^{\circledR}$ White Rum $(750 \mathrm{ml}$ bottle) because it is well known worldwide. A certified rum was used in order to guarantee that it was not adulterated prior to our experiments, and the percentage of alcohol by volume was $40 \%$ as indicated in the rum label. We should also mention that in the market we can also find other rum presentations ranging from $375 \mathrm{ml}, 750 \mathrm{ml}, 980 \mathrm{ml}, 1750 \mathrm{ml}$, $2000 \mathrm{ml}$, and 3 liters, all of them having $40 \%$ of alcohol by volume. However, changes on the

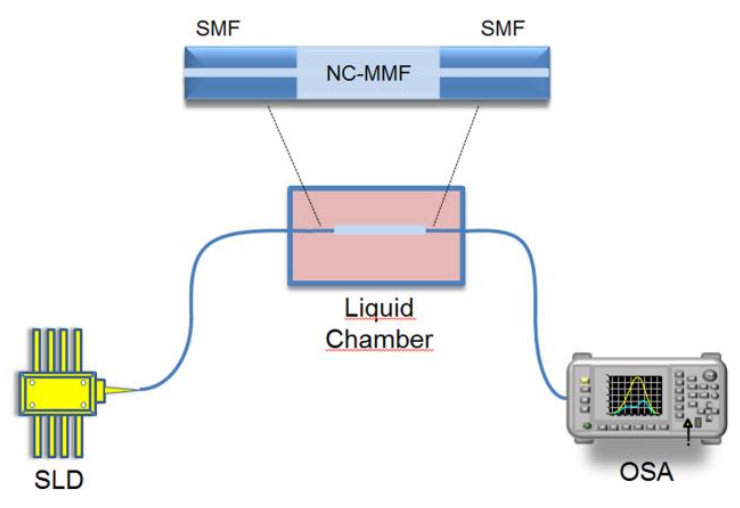

Fig. 3. Experimental setup for testing MMI sensors. 
optical properties of the rum due to the presentation are not expected as long as they belong to the same batch. In the case of different production batches, slight changes could be expected due to slight fluctuation during the fabrication processes.

The response of a MMI sensor immersed in liquids with different refractive indexes was evaluated to obtain the sensitivity of the sensor. The MMI sensor was designed and fabricated as detailed in section 2. Mixtures of water and glycerin were prepared at different proportions to obtain a range of liquids with refractive indexes ranging from $n=1.318$ (100\% Water) to $n=1.4203$ (30\% water $/ 70 \%$ glycerin) $[23,24]$. As shown in Fig. 4(a), the peak wavelength is red shifted as the RI of the liquid is being increased. Since both effective RI and diameter of the NCMMF are being altered, the quadratic behavior means that the diameter is the dominating factor since it has a square dependence. Since adulteration of rum will basically modify the RI of the rum, the sensor is well suited for such application. A sensitivity of $258.06 \mathrm{~nm} / \mathrm{RIU}$ can be estimated from Fig. 4(a). This device is also used to obtain the RI of rum, anhydrous ethanol, and ethylene glycol. This is performed by correlating the MMI peak wavelength shift that is experimentally observed with their corresponding refractive index obtained in Fig. $4(\mathrm{a})$, and their values are shown below.

The spectral response of the MMI sensor for the liquids involved in our experiments are shown in Fig. 4(b). As shown in Fig. 4(b) [black line] the peak wavelength in air is at $1552.3 \mathrm{~nm}$ which is very close to the design wavelength of $1550 \mathrm{~nm}$. The difference can be attributed to slight differences in RI and diameter, as well as to the errors in the NC-MMF length due to our cleaving stage. Nevertheless, MMI devices fabricated afterwards exhibit the same peak wavelength and the error can be easily eliminated. When a sample of rum $(n \sim 1.345$, $\lambda=1550 \mathrm{~nm}, T=25^{\circ} \mathrm{C}$ ) is inserted in the channel we can observe a wavelength shift of $12.67 \mathrm{~nm}$, with the peak wavelength at $1564.9 \mathrm{~nm}$. This peak wavelength is our reference when the rum has not been adulterated. When the sensor is exposed to anhydrous ethanol ( $n \sim 1.3464$, $\lambda=1550 \mathrm{~nm}, T=25^{\circ} \mathrm{C}$ ) provided by Sigma-
Aldrich $₫$, the MMI peak wavelength is shifted to $1566.7 \mathrm{~nm}$. Although the shift is relatively small $(\sim 1.8 \mathrm{~nm})$ it can be easily resolved by the OSA. The largest wavelength shift is observed when EG $\left(n \sim 1.412, \lambda=1550 \mathrm{~nm}, T=25^{\circ} \mathrm{C}\right)$ provided by Sigma-Aldrich $\AA$ is covering the sensor and exhibiting a wavelength shift of $25.5 \mathrm{~nm}$. Based on these results we should be able to identify when a rum sample has been adulterated, by comparing the measured peak to our pure rum reference. As we highlighted before, although the sensor does not determine if the liquid is anhydrous ethanol or EG, it is capable of resolving if the original rum has been altered even for small amounts of liquid. We should highlight that we are using anhydrous ethanol, rather than standard ethanol, because ethanol has a tendency to adsorb water and this can alter his RI value. We should notice that, in principle, the peak intensity should increase as the RI is being increased due to the reduction of scattering losses. In our case, we believe that the
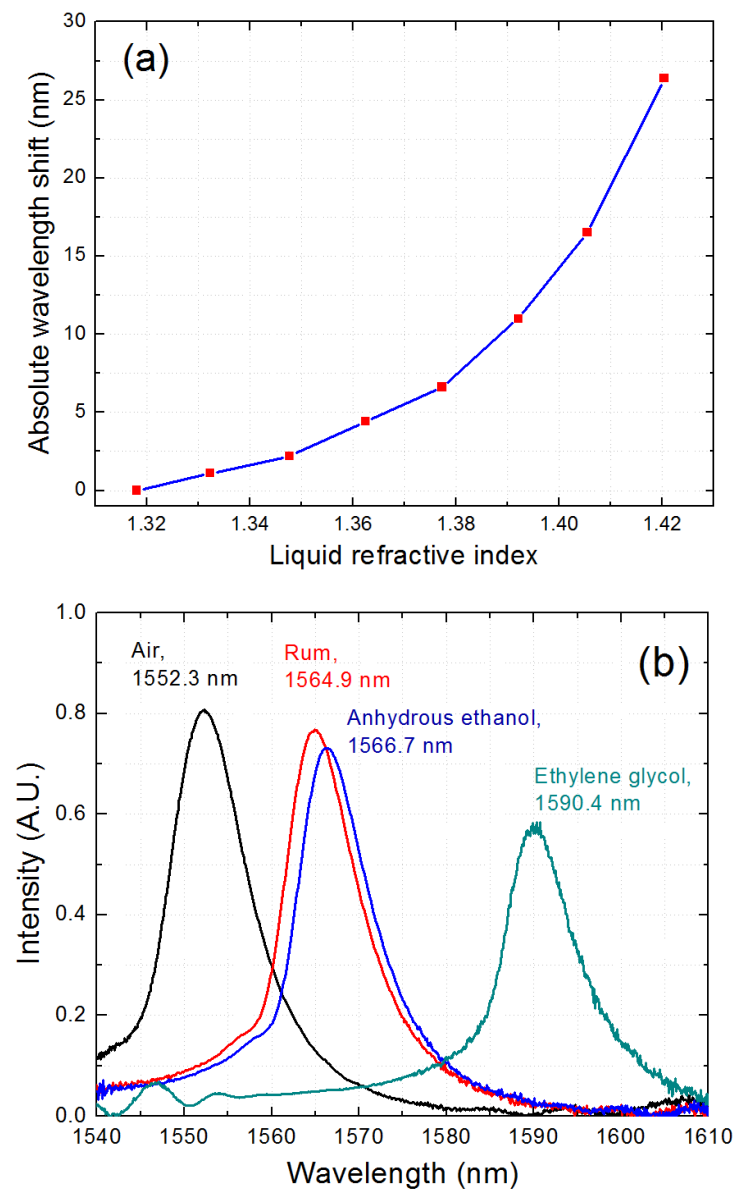

Fig. 4. Experimental setup for testing MMI sensors. 
signal is reduced due to a small bending of the fiber which does not affect the peak wavelength at all.

\section{Results and discussion}

The simplest way to adulterate rum is adding certain amounts of ethanol since industrial ethanol is relatively inexpensive. We prepared solutions of rum with different volumes of anhydrous ethanol. The starting point is $10 \mathrm{ml}$ of pure rum, and we replace certain volumes with anhydrous ethanol. As shown in Fig. 5(a), as the volume of anhydrous ethanol is increased the spectral response is shifted to longer wavelengths. Although this shift is relatively small $(\sim 1.5 \mathrm{~nm})$, it provides a clear indication that the rum has been adulterated as compared to pure rum. Despite the fact that this shift is
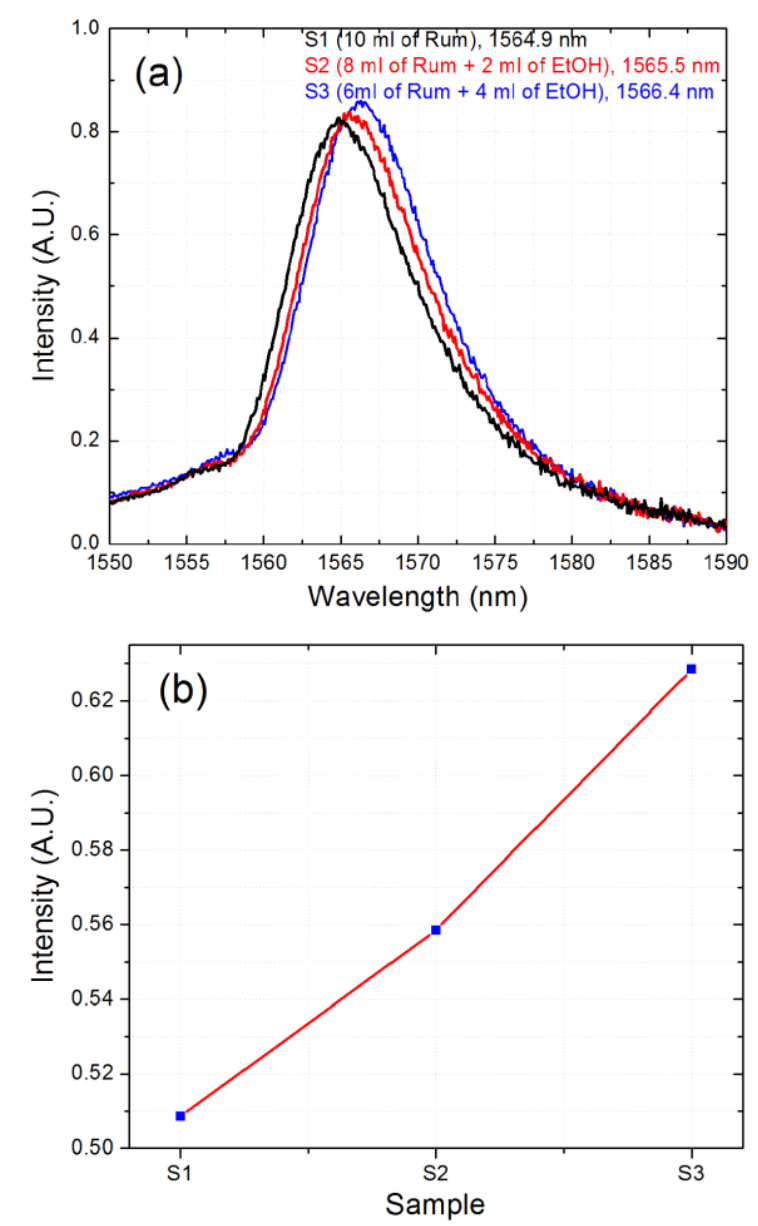

Fig. 5. (a) Spectral response of the MMI sensor for different concentrations of Rum with anhydrous ethanol, and (b) Intensity as a function of the ethanol concentration (sample number). easily resolved by the OSA, a simpler way to measure this small shift is by monitoring intensity changes at one of the steepest walls of the spectrum. In order to avoid intensity fluctuations we applied enough tension to the device to keep the fiber straight during liquid insertion and removal. As shown in Fig. 5(a), we have two options to measure intensity changes, for instance, we tracked the intensity changes at $1570 \mathrm{~nm}$ by using the spectrums obtained from the OSA and the results are shown in Fig. 5(b). We can observe that the contamination with ethanol can be clearly identified and the response is quite linear. The advantage of this approach is that we eliminate the need of an OSA and can operate with a single diode laser and a photo-detector.

The use of EG as an adulterant has also been detected in different alcoholic beverages. In fact, in 1985 there was a well-known case in Europe due to the adulteration of Italian and German wines with EG. Based on the large spectral shift between rum and EG shown in Fig. 4, we should be able to detect quite easily small quantities of EG in rum. Taking $10 \mathrm{ml}$ of rum as the starting volume, we prepared different solutions where the EG was increased in volumes of $1 \mathrm{ml}$ while the same amount of rum was reduced. As shown in Fig. 6, a spectral shift of $1.3 \mathrm{~nm}$ is easily observed even for $1 \mathrm{ml}$ of EG, while an absolute wavelength shift of $7.7 \mathrm{~nm}$ is observed when the volume of rum has been replaced with EG by $50 \%$. As mentioned before, the intensity variations that we observe in Fig. 6 are related to

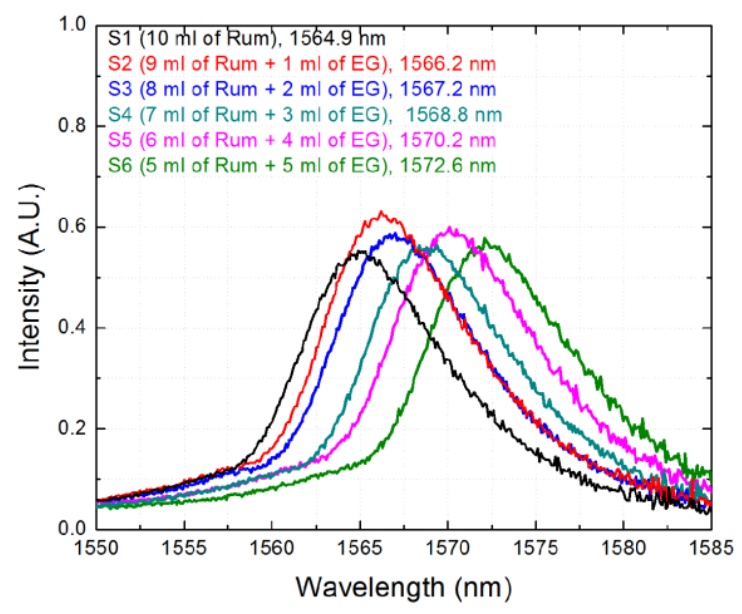

Fig. 6. Spectral response of the MMI sensor for different concentrations of Rum with ethylene glycol. 
slight movement (bending) of the NC-MMF, which can be solved by applying more tension to the fiber when it is glued to the channel. A similar approach to follow intensity changes can be also applied as long as such external intensity variations are eliminated as explained before.

It is well known that the sensitivity of MMI sensors can be increased by reducing the diameter of the NC-MMF [21]. According to Eq. (1), if the diameter of the NC-MMF is reduced then its length has to be reduced to obtain the same MMI peak wavelength. Therefore, using Eq. (1) we can calculate the required NC-MMF length for a diameter of $80 \mu \mathrm{m}$ and peak wavelength of $1552.5 \mathrm{~nm}$, which result in a NCMMF length of $23.81 \mathrm{~mm}$. A second MMI sensor with a NC-MMF length of $23.81 \mathrm{~nm}$ was fabricated and the diameter of the NC-MMF was reduced by immersing the fiber in buffered oxide etching (BOE) solution, which is a mixture of hydrofluoric acid and ammonium fluoride as the buffer agent. Since the etching rate is relatively slow $(\sim 130 \mathrm{~nm} / \mathrm{min})$, we can monitor the transmitted spectrum in real time. After a total time 170 min we can observe that the MMI peak wavelength is at $\lambda=1552.5 \mathrm{~nm}$. The new MMI sensor with reduced diameter was tested again for the rum, anhydrous ethanol, and EG. As shown in Fig. 7, the peak wavelength shift is increased for all the liquids, but is more significant as the RI of the liquid is higher. In particular, we can notice that the peak wavelength separation between rum and anhydrous ethanol is increased to $3.7 \mathrm{~nm}$. The main issue when the NC-MMF diameter is reduced is related to the fact that the band-pass response gets broader, which makes more difficult to identify the exact peak of the bandpass response and imposes a limit in the final diameter that can be reduced. Therefore, for small spectral shift intensity changes are better, while for large shifts spectral works better.

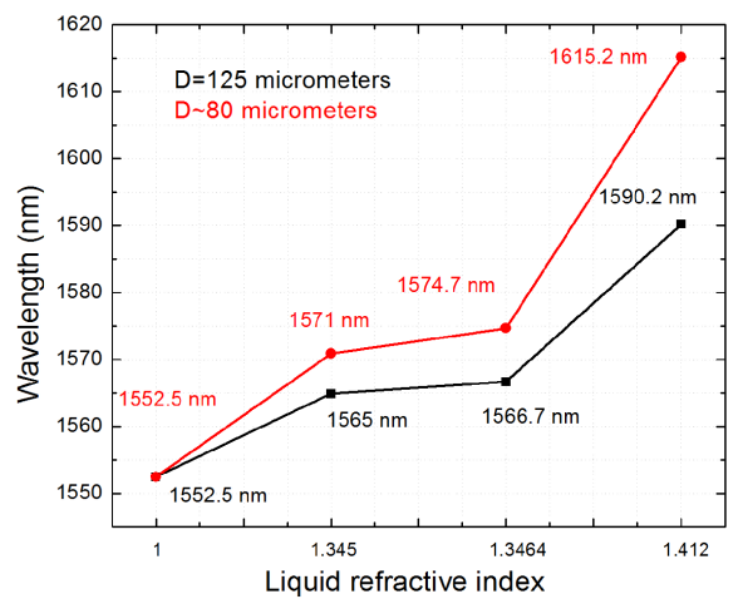

Fig. 7. MMI peak wavelength shift as a function of the liquid RI for different NC-MMF diameters..

\section{Conclusions}

We demonstrated the application of a MMI fiber as a tool for monitoring the quality control of rum. The sensor can detect the adulteration of rum due to presence of ethylene glycol and anhydrous ethanol. The sensor can be spectrally or intensity operated as long as external intensity fluctuations are removed from the experimental setup. The advantages of the sensor are that its fabrication is straightforward, and exhibits great reproducibility and reversibility, with no significant interference against temperature or humidity. We also explored the feasibility of enhancing the sensor response by reducing the diameter of the NCMMF.

\section{Acknowledgments}

We appreciate the support from the Consejo Nacional de Ciencia y Tecnología (CONACyT) under contract CB-2010/157866. This work was also supported by the Spanish Economy and Competitivity Ministry-FEDER TEC2010-17805. 